Session 1566

\title{
Integration of Instruction on the use of Multimedia Tools into a Mechanical Engineering Curriculum
}

\author{
Madara Ogot \\ Department of Mechanical and Aerospace Engineering \\ Rutgers, The State University of New Jersey
}

\begin{abstract}
Mechanical engineering curriculums do not offer formal instruction in the use of multimedia tools in the areas of computer illustration, animation, and image manipulation nor the creation and editing of digital video, despite their prevalent use in industry for technical communication - written reports and oral presentations. In addition to knowing how to use these tools, it is important for mechanical engineering students to understand the terminology associated with their use. For example, at the beginning of the class, most of our mechanical engineering students did not know the difference between a .jpeg or a .gif graphical file, or an .mpeg or a .ram video file. Others could not associate .jpeg or .mpeg with either file type. This paper presents our experience with incorporating formal instruction in the use of multimedia tools into a reverse engineering course. The main aim of the multimedia initiative was for the students to not only learn how to use the tools, but for them to actually use them in other academic activities beyond the reverse engineering class. Evaluations performed indicate that the majority of students did use the tools (especially illustration and image manipulation) in other classes.
\end{abstract}

\subsection{Introduction}

A typical mechanical engineering curriculum does not offer formal instruction in the use of multimedia tools in the areas of computer illustration, animation, and image manipulation, nor the creation and editing of digital video. Yet these technologies are playing an increasing role in industry, especially for technical communication. Using visual content to effectively communicate complex engineering processes or the results from physical and numerical experiments can take on the form of illustrations and images in written documents or embedded (or standalone) video and animations in oral presentations.

In the late seventies to early eighties mechanical engineering students hand-wrote their reports and then employed the services of a typist to generate the final document. Hand-drawn illustrations and photographs, where required, were glued into the final 
document. Technical presentations used hand-written overheads with a few hand-drawn figures.

As personal computers and user-friendly word processing software became commonplace across college campuses in the mid to late eighties, mechanical engineering students transitioned from typed to computer-generated reports. Illustrations and images, however, were still manually generated and glued into the final document. The nineties ushered in the 'Information Technology Age' that saw a significant decline in the price of personal computers - resulting in increased numbers in college computer laboratories as well as student dorm rooms - accompanied by a myriad of user friendly, relatively inexpensive software tools for animation, illustration, presentation, video editing and image manipulation. At the same time enabling hardware such as scanners and digital cameras (still and video) became everyday consumer products.

The use of these "Information Technology Age" multimedia tools by mechanical engineering students has, however, lagged far behind their rate of development or their use in industry. Several specific areas can be identified:

1. Although mechanical engineering students now generate electronic illustrations for their reports and presentations, the tools they use are typically either inadequate (for example using the drawing tools in Microsoft Word $\mathrm{B}$, primarily a word-processing tool, resulting in relatively poor images) or inappropriate (for example the use of Computer-Aided Design (CAD) software such as Pro/Engineer to create relatively simple 2-Dimensional illustrations).

2. Image generation hardware - scanners and cameras - have made image creation and importation into the computer relatively simple. Mechanical engineering students, however, have difficulty in correctly incorporating the images into their reports or presentations. Over the last few years the author has observed that students struggle (if they try at all) in editing, enhancing, annotating or manipulating their images before embedding them into their reports or presentations. It has been quite common for students electronically submitting 23 page progress reports or 10-20 page term papers to send files several megabytes in size. This is because they (a) were unaware or unable to reduce the dimensional size (and therefore the corresponding file size) of the image or (b) do not crop the images (resulting in both dimensional and file size reductions) to focus only on the area of interest, before embedding them into the documents.

3. In addition to knowing how to use these tools, it is important for students to understand the terminology associated with their use. For example preliminary surveys of students in this study found that most did understand what a pixel was, how digital images are stored, different types of image and video digital formats, or the difference between screen and print resolution.

Providing formal instruction on the use of these tools presents its own challenges:

4. In an already packed mechanical engineering curriculum, where can formal instruction in multimedia tools be added? What would it replace? Further, as stated in Vest et al. ", "Increasing students' communication competence at the expense of adequate technical training is not ... a viable approach". Yet numerous surveys of engineers in industry consistently place a high priority on 
ensuring that students are proficient in technical communication ${ }^{2-4}$ and as we enter the Information Technology Age, I believe that technical communication instruction must include the use of appropriate multimedia tools.

5. Finding faculty able or willing to teach students how to use these tools. As stated in Vest et al. ${ }^{1}$, “...engineering faculty may neither be able...to allocate time specifically for communication skills training nor be comfortable teaching specialized communication skills."

6. Finding appropriate instructional materials. Commercially available books tend to focus on a single tool in great depth. In order to provide instruction on an animation tool, an illustration tool, an image manipulation tool, and a video editing tool students would need to buy four books (at a total price tag of $\sim \$ 160$ ).

\subsection{Reverse Engineering with an Introduction to Multimedia Tools}

The solution adopted at Rutgers University, is to incorporate formal multimedia instruction into a reverse engineering course. The course was open to sophomores, juniors and seniors in Mechanical Engineering. The enrollment was limited to twelve students initially, primarily due to the initial capital outlays required for the equipment, but will gradually be increased as the course matures. Typical reverse engineering courses are modular in nature, with students dissecting several devices per semester where the dissection steps are well laid out and the associated theoretical foundation discussed in lecture. Such an approach allows the courses to be introduced fairly early in the students' academic career ${ }^{5,6}$. The model adopted here, however, was more openended. The dissection steps were not laid out nor detailed background materials on the devices or systems under investigation provided.

At the beginning of the semester, students groups were handed a mechanical device to dissect, some basic tools, digital still and a digital video camera. Examples of mechanical devices dissected include an industrial nailer, a bread maker and a two-stroke engine weed-wacker. Based on their research, the student teams determined the associated theoretical foundation, the rationale behind the design and the best dissection steps necessary to establish how their devices worked. This approach allowed the students to directly apply their previous classroom knowledge and the results of their own research to solve the problem. Using the digital and video camera, each group documented the entire dissection process and recorded different systems in operation. Each group was then required to created a fifteen-minute digital video documentary on DVD detailing the history of the device, how it works and possible improvements. Their documentaries had to incorporate animations, illustrations, still images, and of course, digital video.

As the students embarked on their product dissection projects, they received concurrent formal instruction on reverse engineering, the use of four common multimedia tools, and common multimedia terminology and definitions. Although the actual software will change from year to year, students were exposed to Adobe Photoshop ${ }^{\circledR}$ (image manipulation), Adobe Illustrator ${ }^{\circledR}$ (illustration), Macromedia Flash ${ }^{\circledR}$ (animation) and iMovie $2^{\circledR}$ (digital video editing).

Engineering educators have long noted that lectures though efficient at delivering

large amounts of analytical information, encourage passivity in students who come to

Proceedings of the 2003 American Society of Engineering Education Annual Conference \& Exposition Copyright (C) 2003, American Society of Engineering Education 
expect the instructor to provide all the required knowledge ${ }^{6}$. Johnson et al. ${ }^{7}$ noted that: "lecturing at best tends to focus on the lower-level of cognition and learning. When the material is complex, detailed or abstract; when students need to analyze, synthesize, or integrate the knowledge being studied; or when long term retention is required, lecturing is not such a good idea." Other researchers have found that lectures tend to alienate active and reflective learners - the active learners do not do anything, while the reflective learners do not have time to reflect. As a result, both are lulled into inattention by enforced passivity ${ }^{8,9}$. Also, lectures do not adequately take into account varied student learning styles ${ }^{10,11}$. Many engineers are actually "active, visual learners", much better served by active, visual and tactile teaching methods ${ }^{12-15}$.

During Summer 2002, the author developed several tutorials that taught students the basics of each tool. Unlike most software books that simple discuss the various commands, sprinkled with examples, a project-based approach was adopted to introduce the students to the tools. As the students progressed through each project, new commands and techniques were introduced. On completion of each project, the students had the basic knowledge to be able to (1) use the tools at an intermediate level, and (2) explore and try out different features that were not explicitly covered. As an example, Figure 1 shows the final illustration created on completion of the Illustrator ${ }^{\circledR}$ tutorial.

Students completed each project as a homework problem, each taking $\sim 2-3$ hours to complete. Every student therefore turned in an individual project using each tool ensuring that they had all been adequately exposed to all tools. In addition to step-bystep instructions on the individual tool projects, the tutorials also contained background information on image, sound and video formats, color definitions for online or print viewing, discussions on image resolutions, file size, etc. The tutorials are available on the course website, http://mechanical.rutgers.edu/cdw/. In addition, clips from the video documentaries can be found on the site.

\subsection{Evaluation: Application and Long-term Retention}

As stated at the outset of the paper, the major goal was to expose students to the use of multimedia tools and increase the tools use by the students in their technical communications (primarily written reports and oral presentations). A preliminary assessment on whether these goals where achieved was done via two surveys: One performed on the first day of Fall 2002 class, and the second on the last day. To avoid any biases in the results from students intentionally studying for the surveys, students were not informed ahead of time about either survey. In addition, the survey's where anonymous increasing the likelihood of truthful answers.

The first three questions on the survey focused on general knowledge essential in understanding the nature and the use of multimedia tools. An aggregate of the results are presented in Table 1. Clearly one can observe that over two-thirds of the students had the correct basic knowledge on the role of pixels and resolution in digital imaging at the end of the semester as compared to one-third or less at the beginning of the semester.

The second set of questions administered only at the end of the semester, wanted to determine how many students had used any of these tools (or similar) prior to taking this class, and how many had used the tools learnt in other classes. The first question, "Have you used any of these or similar tools in any of your classes prior to this 


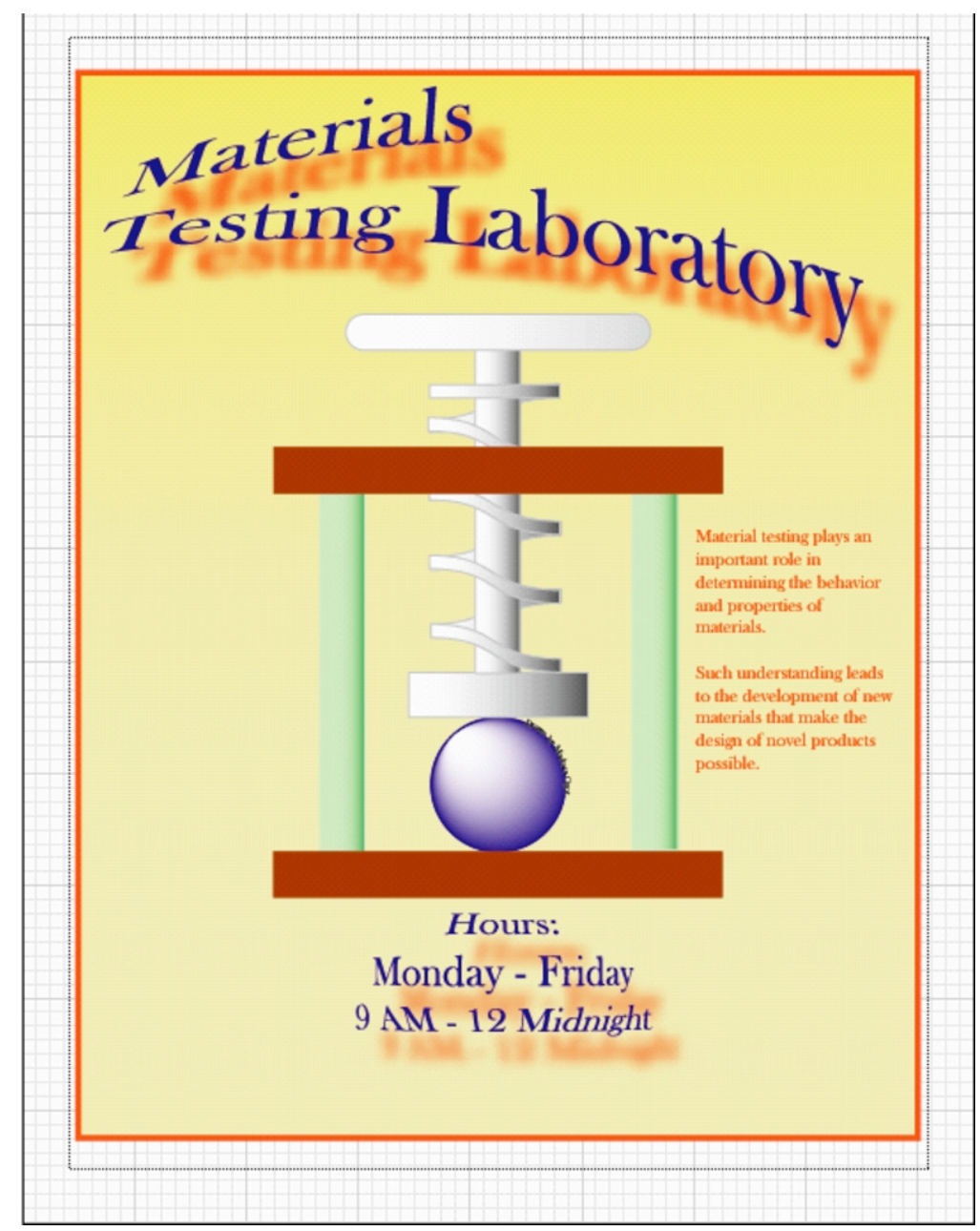

Figure 1. Illustration after completion of Illustrator ${ }^{\circledR}$ project

Table 1. Aggregate survey results relating to basic understanding of digital images (Cor. - Correct answer given; Inc. - Incorrect answer given)

\begin{tabular}{|l|c|c|c|c|}
\hline Question & \multicolumn{2}{|c|}{ Beginning } & \multicolumn{2}{c|}{ End } \\
\hline & Cor & Inc. & Cor. & Inc. \\
\hline 1. What is a pixel? & 3 & 9 & 8 & 4 \\
\hline $\begin{array}{l}\text { 2. When you scan a photograph, one of your options is to } \\
\text { select how many pixels/inch you want the scanned image to } \\
\text { have. What does this mean? }\end{array}$ & 3 & 9 & 7 & 5 \\
\hline $\begin{array}{l}\text { 3. How does increasing the pixels/inch affect the quality of } \\
\text { the image? }\end{array}$ & 4 & 8 & 10 & 2 \\
\hline
\end{tabular}


semester?" resulted in a "yes" answer from 4 students $(33.3 \%)$ of the class. For the eight students who answered "no", the follow up question asked, "Have you used any of the tools you learnt in this class in any of your other classes?" Of the eight, five answered "yes" and three answered "no". Thus after one semester, starting with only four (33\%) having used any of the tools for classwork, we ended up with nine or $75 \%$.

\subsection{Concluding Remarks}

This paper articulates the importance of exposing mechanical engineering students to the use of multimedia tools as a means to effectively convey complex engineering ideas and results by adding rich visual content to written reports and oral presentations. Instruction on the use of these tools was incorporated into a mechanical dissection course at Rutgers University. It is too early to evaluate any long-term impact the course will have on students' technical communication skills. We will, however, send out follow-up surveys, similar to the ones presented here, at the end of each semester to students who have taken the class. The results of the survey should provide an indication as to whether providing formal instruction in the use of multimedia tools actually translates into their common use by students during their technical oral and written communications. The preliminary evaluations presented here indicate that this may be the case.

The material and tutorials can be easily be covered in one week of lectures and two weeks of homework - all four projects took $\sim 8-12$ hours in total to complete. They could therefore be incorporated into introductory engineering classes, for example freshman engineering design courses. The tutorials now form part of a new book, iMovie3, Flash MX, Photoshop 7 and Illustrator 10: A Project-based Introduction from Trafford Publishers, making it unnecessary to purchase four books to cover the material. Instructors unfamiliar with these tools could themselves complete the projects and read through the background material and be prepared to introduce the tools into their courses.

\section{Acknowledgment}

The author would like to acknowledge the National Science Foundation for support of this project through a grant number CCLI0088891.

\section{References}

1. Vest, D., Palmquist, M. and Zimmerman, D., "Enhancing Engineering Students' Communication Skills Through Multimedia Instruction,” Journal of Engineering Education, vol. 84, no. 4, October 1995, pp. 383-387.

2. Dahir, M., "Educating Engineers for the Real World", Technology Review, vol. 96, August/September, 1993, pp. 14-16.

3. Evans, D.L., Beakley, G.C., Crouch, P.E., Yamaguchi, G.T., “Attributes of Engineering Graduates and their Impact on Curriculum Design", Journal of Engineering Education, vol. 82, no. 4, October 1993, pp. 203-211.

4. Pinelli, T.E., Barclay, R.O., Keene, M.L., Kennedy, J.M., and Hecht, L.F., "From Student to Entry-Level Professional: Examining the Role of Language and Written Communications in the 
Reacculturation of Aerospace Engineering Students," Technical Communication, vol. 42, no. 3, 1995, pp. 492-503.

5. Shepard, S. D., 'Mechanical Dissection: An Experience in How Things Work' Proceedings of the Engineering Education Conference on Curriculum Innovation and Integration, 1992.

6. Lamancusa, J, M., Torres, V. Kumar and J. Jorgensen, 'Learning Engineering by Product Dissection' Proceedings of ASEE Annual Conference, 1996, pp. 1-12.

7. Johnson. D.W., R. T. Johnson and K.A. Smith, Active Learning: Cooperation in the Classroom, Interaction, Edina MN, 1991.

8. Kolb, D., Experiential Learning: Experience as the Source of Learning and Development. Prentice-Hall, Englewood Cliffs, 1984.

9. Felder, R.M., 'Reaching the Second Tier-Learning and Teaching Styles in College Science Education', Journal of College Science Teaching, vol. 23, no. 5, March/April, 1993, pp. 286-290.

10. Mestre, J.P. "Cognitive Aspects of Learning and Teaching Science' Pre-College Teacher Enhancements in Science and Mathematics: Status, Issues and Problems, S.J. Fitzsimmons and L.C. Kerpelman (Eds.), National Science Foundation, Washington, DC, 1991.

11. Koen, B.V., 'Toward a Strategy for Teaching Engineering Design', Engineering Education, vol. 83, no.3, 1994, pp. 193-202.

12. Felder, R.M. and L.K. Silverman, "Learning and Teaching Styles in Engineering Education" Engineering Education, vol. 78, no. 7, April 1988, pp. 674-681.

13. Svinicki, M.D. and Dixon, N.M. 'The Kolb Model Modified for Classroom Activities', College Teaching, vol. 35, no. 4, 1991, pp. 141-146.

14. Myers, C. and T. Jones, Promoting Active Learning: Strategies for the College Classroom, JosseyBass, San Francisco, 1993.

15. Wankat, P.C. and Oreovicz, F.S., 'A Different Way of Teaching' ASEE Prism, January 1994, pp. 15-19.

\section{Biography}

MADARA OGOT is an associate professor in Mechanical Engineering at Rutgers University where he serves as Undergraduate Director. His current research interests include design under uncertainty and recovery of energy from ocean waves. He received his BSE from Princeton in 1987, and his MS and Ph.D. from the Pennsylvania State University in 1989 and 1991, respectively. 